\title{
A Laboratory Strain of Leishmania major: Protective Effects on Experimental Leishmaniasis
}

\author{
Mehdi Namavari ${ }^{1} \cdot$ Fatemeh Namazi $^{2} \cdot$ Reza Asadi-Manesh ${ }^{3} \cdot$ Mohammad H. Hosseini $^{1} \cdot$ Saeed Nazifi ${ }^{4}$. \\ Mohammad Asadpour ${ }^{2}$
}

Received: 10 July 2018 / Accepted: 6 May 2019 / Published online: 20 May 2019

(c) Witold Stefański Institute of Parasitology, Polish Academy of Sciences 2019

\begin{abstract}
Purpose Leishmaniasis, as one of the most important vector-borne and zoonotic diseases, can be seen in different forms and is more prevalent in developing countries worldwide. Due to the absence of effective strategies in its prevention, treatment, and control, investigation of effective control strategies against the disease is necessary. In this research, we evaluated the immunogenicity of a cold-adapted laboratory strain of Leishmania major (LMC) in the mouse model.

Methods Twenty BALB/c mice were divided into two groups. LMC group received $4 \times 10^{6}$ of LMC strain in $0.5 \mathrm{ml}$ DMEM, and VLM group, as the control group, received $0.5 \mathrm{ml}$ Dulbecco's modified Eagle's medium. Both groups were challenged with virulent $L$. major 3 weeks after inoculation.

Results The data obtained from the analysis of immune responses and histopathological changes interestingly revealed protection against L. major in immunized mice. Compared with the VLM group, the mice immunized with LMC strain of L. major in the LMC group showed a significant increase in IFN- $\gamma$ and IgG2a levels $(P<0.05)$ which are important indexes for Th1-related immune responses. Additionally, significant differences in concentration of IgG1 and IgG total before and after the challenge was observed in LMC group $(P<0.05)$. Furthermore, the immunized mice showed a significant reduction in mean sizes of skin lesion and liver damage compared to the VLM group.

Conclusion Based on the present findings on immunogenicity of LMC strain, it seems this strain is able to induce both humoral and cellular immunity and a significant protection against $L$. major in the mouse model.
\end{abstract}

Keywords Leishmania major $\cdot$ Cold-adapted laboratory strain $\cdot$ Immunogenicity $\cdot$ Histopathology $\cdot$ BALB/c mice

\section{Introduction}

Leishmaniasis is considered endemic in 98 countries, including some of the poorest population in the world. Based on the World Health Organization (WHO) reports, approximately more than 12 million people are currently infected

Fatemeh Namazi

fnamazi@shirazu.ac.ir

1 Razi Vaccine and Serum Research Institute, Shiraz Branch, Agricultural Research, Education and Extension Organization (AREEO), Shiraz, Iran

2 Department of Pathobiology, School of Veterinary Medicine, Shiraz University, Shiraz, Iran

3 School of Veterinary Medicine, Shiraz University, Shiraz, Iran

4 Department of Clinical Sciences, School of Veterinary Medicine, Shiraz University, Shiraz, Iran with leishmaniasis and over 350 million people are at the risk of catching the disease around the world. The disease is transmitted by the bite of phlebotomine sand flies. Cutaneous leishmaniasis (CL), caused by Leishmania major, is the most common form of the disease as it is the case in Iran, Afghanistan, Syria, Saudi Arabia. and Algeria [1, 41, 43]. The skin sores caused by CL appear as papules or nodules on the sand fly bite and may end up as skin ulcers and scab formation. Various forms of drugs are available for the treatment of human leishmaniasis; however, treatments such as pentavalent antimonials compounds are toxic and very expensive for those infected. Moreover, treatment failures and incidence of drug resistance are common. The aforementioned side effects and problems in chemical treatment strategies highlight the need for a valuable and safe vaccine, which produces long life immunity [22, 30, 43]. Therefore, many studies have focused on the development of an effective vaccine as a feasible solution. Over the past 
two decades, different vaccine forms and molecule candidates such as the entrapped-in-liposomes recombinant gp63 [18], killed whole-parasites as first generation vaccines [17, 19, 20], and L. major secreted-excreted exogenous antigens have shown signs of protecting animals against experimental leishmaniasis [41]. Nevertheless, to date, there is no licensed vaccine available against any form of human leishmaniasis $[10,18,24]$. More recent investigations in L. major-resistant mouse have indicated complexities in the responsible mechanisms for acquired immunity, which highlights the need to redesigning of vaccines against Leishmania that require sustained cell-mediated immune responses [33, 34]. Live-nonattenuated vaccines (an old strategy) in the hyper-endemic Asian countries are known as an effective way to protect people against further lesions. In these endemic areas, leishmanization (LZ) was used to develop a self-healing lesion and consequently to protect people against lesions on the face and other exposed parts of the body, especially in children [9, 20, 26, 28]. Adverse side effects of LZ including the development of large, persistent lesions led to the discontinuation of LZ in many countries and the focus of vaccine development projects, consequently, changed towards killed or live-attenuated vaccines $[7,12,16]$. Nowadays, genetic manipulation of Leishmania parasites to reduce virulence, together with maintaining immunogenicity, is an appealing prospect in Leishmania vaccine research. Live-attenuated vaccination is closely similar to a natural infection that may lead to the same immune responses, and there is minimal risk associated with infection by live virulent parasites [12, 16].

Recently, an interesting strain of L. major was prepared by a long-term serial passage in low temperature condition in Razi Vaccine and Serum Research Institute, Shiraz branch, Iran. This cold-adapted laboratory strain of Leishmania major was named L. major cold strain (LMC). Previous pilot studies have indicated LMC was immunogenic and no pathogenic effect was observed [2]. In the present study, the ability of LMC strain to induce an immune response and as a protection against $L$. major infection in susceptible BALB/c mice was investigated.

\section{Materials and Methods}

\section{Preparation of the Parasites}

The LMC strain was maintained in the Dulbecco's Modified Eagle's Medium (DMEM) (Sigma-Aldrich) with 2\% fetal bovine serum (FBS) (Sigma-Aldrich), supplemented with $50 \mu \mathrm{g} / \mathrm{ml}$ gentamicin (Sigma-Aldrich), $100 \mathrm{U} / \mathrm{ml}$ penicillin G potassium salt (Sigma-Aldrich), and $100 \mu \mathrm{g} / \mathrm{ml}$ streptomycin sulfate salt (Sigma-Aldrich). In addition, Live L. major parasite (for a challenge infection) was taken from the Razi vaccine and Serum Institute (Karaj-Iran), in RPMI 1640 medium (Sigma-Aldrich) with 10\% FBS (Sigma-Aldrich) supplemented with $100 \mathrm{U} / \mathrm{ml}$ penicillin $\mathrm{G}$ potassium salt (Sigma-Aldrich), $50 \mu \mathrm{g} / \mathrm{ml}$ gentamicin (Sigma-Aldrich), and $100 \mu \mathrm{g} / \mathrm{ml}$ streptomycin sulfate salt (Sigma-Aldrich) [3, 42, 44].

\section{Study Design}

Twenty male inbred BALB/c mice at 4 weeks of age, provided by the Pasteur Institute (Tehran, Iran), were housed in separate laboratory cages with optimal conditions $\left(25-27{ }^{\circ} \mathrm{C}\right.$, light/dark cycles in 12 -h interval). Commercial laboratory rodent pellets and water were also available freely. The mice were divided into two groups. LMC group received $4 \times 10^{6}$ of LMC strain in $0.5 \mathrm{ml}$ DMEM and VLM group, as the control group, received $0.5 \mathrm{ml}$ DMEM. All doses were injected subcutaneously into the groin. Three weeks later, both groups were challenged subcutaneously at the base of the tail with $2 \times 10^{6}$ of virulent amastigotes of $L$. major isolated from fresh skin lesion.

\section{Antigen Preparation}

Leishmania major antigens were prepared as described previously $[35,41]$ with some modifications as follows: promastigotes were gained from culture and then washed two times with cold phosphate-buffered saline (PBS). Thereafter, centrifugation was performed twice at $9000 \mathrm{~g}$ for $30 \mathrm{~min}$. The parasites were then sonicated at $1{ }^{\circ} \mathrm{C}(3 \times 60 \mathrm{~s}$ at $65 \mathrm{~W})$. The concentration of proteins in the supernatant was determined by Lowry's method [23] and were stored at $-80{ }^{\circ} \mathrm{C}$ until used.

\section{Immune Response Assay}

ELISA assay was performed to measure anti-Leishmania antibodies (total IgG, IgG1 and IgG2a), before and 14 weeks after the challenge. Briefly, ELISA plate wells were coated with $50 \mu \mathrm{l}$ of $0.5 \mu \mathrm{g} / \mathrm{ml}$ of antigen suspension at $4{ }^{\circ} \mathrm{C}$ overnight. Plates were washed and blocked with $100 \mu \mathrm{l}$ of $1 \%$ BSA in PBS-Tween/well for $1 \mathrm{~h}$ at $37{ }^{\circ} \mathrm{C}$. Serum samples were diluted 1:100 with PBS-Tween and each well was filled with $100 \mu l$ of diluted serum. Then, anti-mouse IgG isotype was added to the plates according to the manufacturer's instructions (Sigma, USA). Then plates were incubated at $37^{\circ} \mathrm{C}$ for $1 \mathrm{~h}$. Thereafter, plates were washed and charged with $100 \mu \mathrm{l}$ of substrate and chromogen mixture and incubated at room temperature in dark for $15 \mathrm{~min}$. The reaction was stopped by adding $100 \mu \mathrm{l}$ of stop solution, that is, $\mathrm{H}_{2} \mathrm{SO}_{4} 12.5 \%$, and the ODs of wells were read at $450 \mathrm{~nm}$ by ELISA reader. The cut-off value was defined as the mean value of the control group plus two standard deviations. 
All mice from each group were killed humanely 14 weeks after the challenge. The spleens of sacrificed mice were aseptically removed and lymphocytes were extracted via high-pressure pumping. The lymphocytes were cultured using $1 \times 10^{6}$ cells per well supplemented with $0.5 \%$ mouse normal sera and DMEM and incubated at $37{ }^{\circ} \mathrm{C}$ with $5 \%$ $\mathrm{CO}_{2}[21,31,41]$. Afterward, cells were stimulated with a $50-\mu \mathrm{g}$ antigen of parasites separately. Secreted IFN- $\gamma$ and IL-4 in supernatants were measured $72 \mathrm{~h}$ after stimulation using a commercial kit based on enzyme-linked immunoassay (ELISA) (Shanghai Crystal Day Biotech Co., LTD, Shanghai, China).

\section{Histopathological Analysis}

Sampling was performed from the injection site, lesions, and liver in all groups. Next, small samples were fixed in $10 \%$ formalin-buffer, embedded in paraffin, sectioned and stained with hematoxylin and eosin (H\&E), and Giemsa stain. A semi-quantitative scoring method was used to evaluate the tissue lesions and following grades were considered: none ( 0 , normal), mild (1, $0-33 \%$ of tissue affected), moderate $(2,34-66 \%$ of tissue affected), and severe $(3,67-100 \%$ of tissue affected) [14].

\section{Statistical Analysis}

Statistical analysis was performed using SPSS v.16 and Graph Pad Prism 6.0. One-way ANOVA, followed by Tukey test, and two-tailed Student's $t$ test were used. Results with $P<0.05$ were considered to be statistically significant. Values were expressed as mean $\pm \mathrm{SD}$.

\section{Animal Ethics}

This experiment was accomplished under the approval of the state committee on animal ethics, Shiraz University, Shiraz, Iran. Also, the recommendations of European Council Directive (86/609/EC) of November 24, 1986 were used regarding the standards in the protection of animals used for experimental purposes.

\section{Results}

\section{Clinical Findings}

Lesion development was recorded from 3 weeks after the challenge started, with 1-week interval until week 14 post challenge. Lesion size development in VLM group was at a more rapid rate than LMC group. The ulcer area indicated a decreasing trend in LMC group in comparison with VLM group. Moreover, significant differences were seen between LMC and VLM groups from 7 weeks post challenge $(P<0.05)$ (Fig. 1).

\section{Histopathological Findings}

The tissue sections of the VLM group showed a moderate to severe diffuse granulomatous dermatitis and mild to severe diffuse hepatitis with the presence of numerous parasites within the lymphocytes, macrophages, and outside the cells (Fig. 2a, b). The skin sections of the LMC group revealed a mild diffuse granulomatous dermatitis and hepatitis. Parasites were rarely observed in cutaneous sections (Fig. 2c, d). The mean \pm SD of histopathological scores was showed in Table 1.
Fig. 1 Lesion development was recorded from 3 weeks after challenge until week 14 with regular intervals. Lesion size rapidly developed in the VLM group, whereas lesion size showed a decreasing trend in LMC group. VLM virulent L. major, LMC L. major cold strain

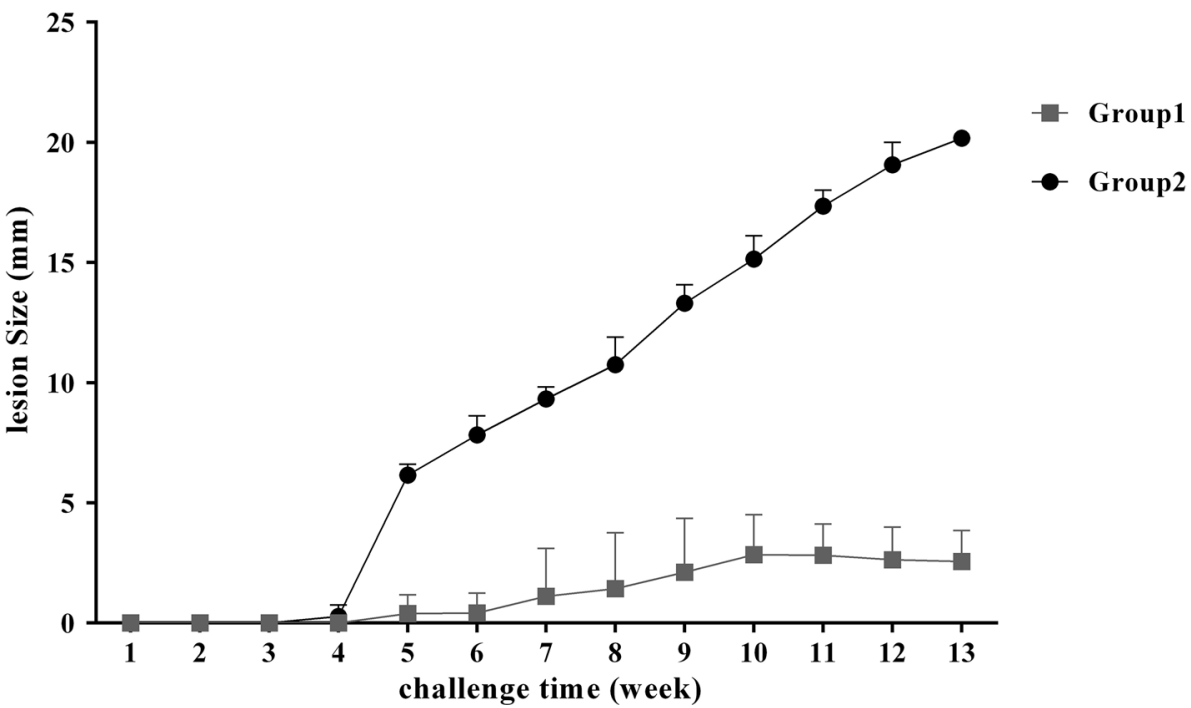


Fig. 2 Skin sections of different groups. a Tissue section of a mouse receiving $L$. major shows severe diffuse granulomatous dermatitis with many macrophages and lymphocytes infiltration (asterisks), $\mathrm{H} \& \mathrm{E}, \times 180$. b There are a large number of Leishman bodies within the macrophages and extracellulary (arrows) in a mouse receiving L. major, Giemsa, $\times 720$. c Tissue section of a mouse received $4 \times 10^{6} \mathrm{LMC}$ strain and challenged by L. major (LMC group) shows mild diffuse granulomatous dermatitis with few inflammatory cells (asterisks), H\&E, $\times 180$. d Parasites (arrow) are rarely observed in the cutaneous section of the mouse of LMC group, $\mathrm{H} \& \mathrm{E}, \times 720$
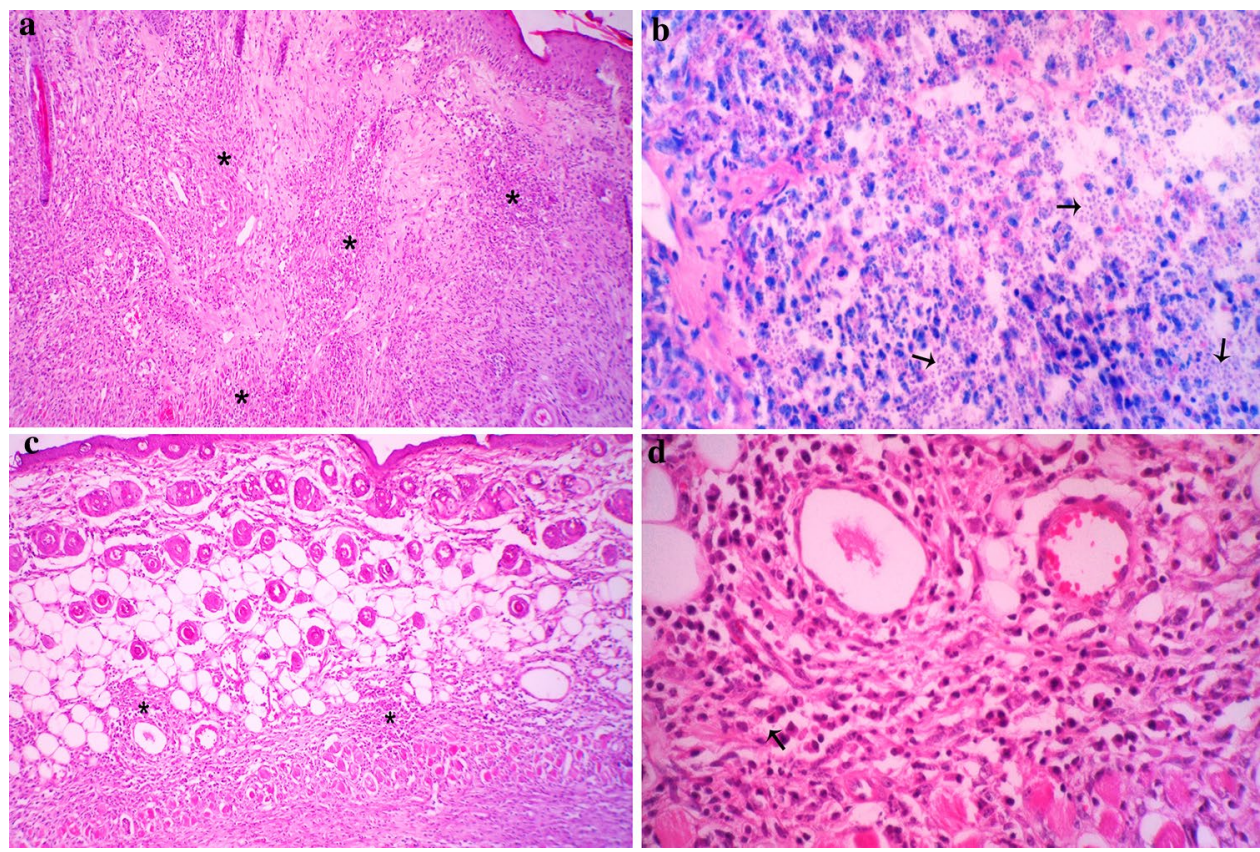

Table 1 Comparison of histopathological scores in experimental groups $($ mean $\pm \mathrm{SD})$

\begin{tabular}{lcc}
\hline Groups & Skin lesions & Liver lesions \\
\hline VLM group & $2.80 \pm 0.42^{\mathrm{a}}$ & $2.40 \pm 0.51^{\mathrm{a}}$ \\
LMC group & $0.90 \pm 0.31^{\mathrm{b}}$ & $0.50 \pm 0.52^{\mathrm{b}}$ \\
\hline
\end{tabular}

Different letters indicate statistically significant differences $(P<0.05)$

$V L M$ virulent $L$. major, $L M C$ L. major cold strain

\section{Immune Response Assay}

In the VLM group, the $\operatorname{IgG} 1$ and $\mathrm{IgG}$ total levels increased and the IgG2a decreased. Also, IgG1 titer was found to be statistically significant $(P<0.05)$ in this group. The concentration of $\operatorname{IgG} 1, \operatorname{IgG}$ total, and especially $\operatorname{IgG} 2 \mathrm{a}$, increased in LMC group, which showed a significant difference before and after the challenge $(P<0.05$ ((Figs. 3, 4 and 5).

The increasing amount of IFN- $\gamma$ was observed in the mice of LMC group which showed a significant difference from the VLM group $(P<0.05)$. Although the IL-4 level increased after the challenge with $L$. major, no significant difference was found between the groups $(P>0.05)$ (Table 2) (Fig. 6).

\section{Discussion}

Given that leishmaniasis is one of the major public health concerns, nowadays prevention, control, and treatment aspects of this disease are the common topics in the recently published research around the world. Due to the various limitations in control strategies and the low efficacy of common

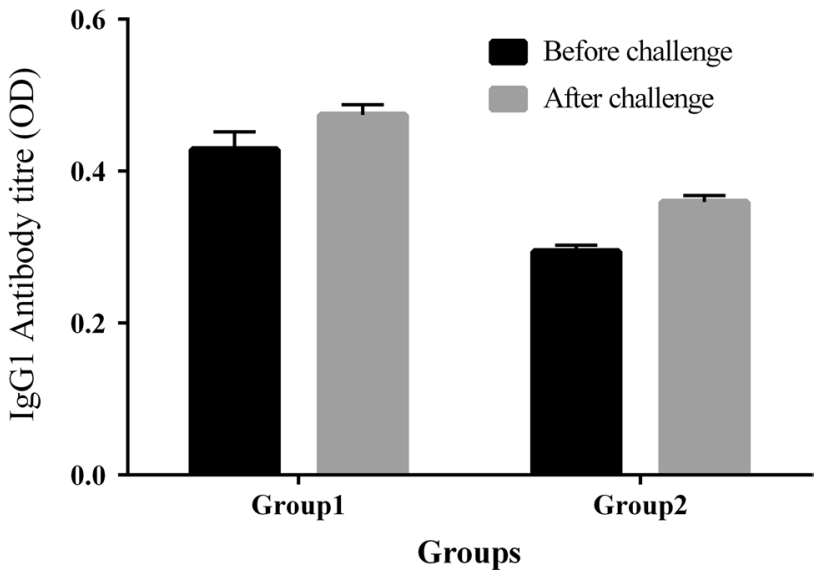

Fig. 3 The IgG1 level in BALB/c mice, before and 14 weeks after the challenge. VLM virulent $L$. major, LMC L. major cold strain

chemotherapy, developing an effective vaccine against three different forms of leishmaniasis seems to be the most logical and effective policy in control strategy [13, 18, 27]. However, despite recent substantial efforts by many researchers on different types of Leishmania vaccines, including killed parasites, mosquito salivary gland antigens, recombinant Leishmania antigens such as L. major stress-inducible protein 1 (LmSTI1) [3, 6], glycoprotein 63 (gp63), and membrane glycoprotein 46 (gp46) $[8,25]$ in experimental models, there is no effective commercial vaccine available [15, 39]. Based on recent investigations, a high degree of protection can be gained by immunization with live-attenuated or first-generation vaccine and/or drug-sensitive strains of Leishmania [13, 29, 37, 38]. Based on the previous studies 


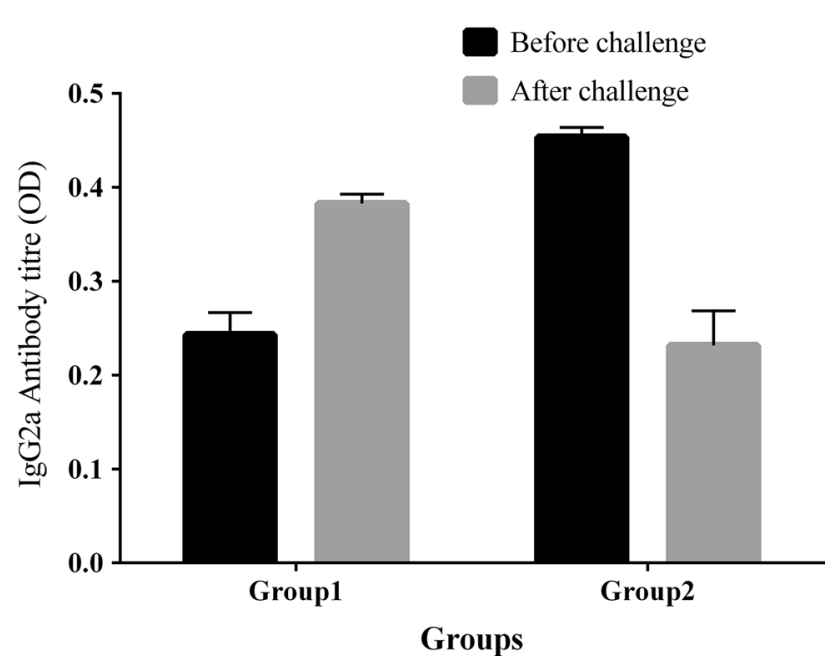

Fig. 4 The IgG2a level in BALB/c mice, before and 14 weeks after the challenge. $V L M$ virulent $L$. major, $L M C L$. major cold strain

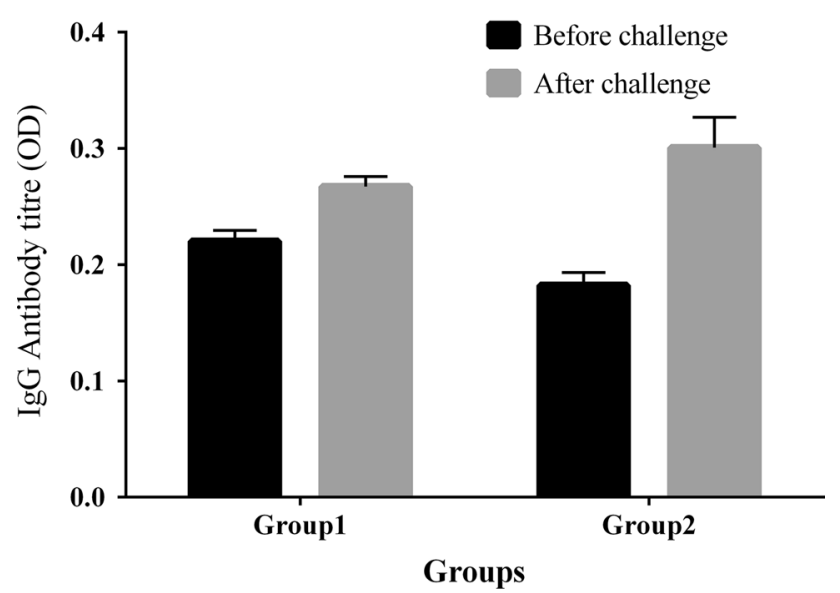

Fig. 5 The IgG total level in BALB/c mice, before and 14 weeks after the challenge. VLM virulent L. major, LMC L. major cold strain

Table 2 The mean \pm SD of parameter values in experimental groups

\begin{tabular}{lll}
\hline Groups & IFN- $\gamma(\mathrm{Pg} / \mathrm{ml})$ & $\mathrm{IL}-4(\mathrm{Pg} / \mathrm{ml})$ \\
\hline VLM group & $396.35 \pm 42.535^{\mathrm{b}}$ & $655.67 \pm 183.49^{\mathrm{a}}$ \\
LMC group & $563.56 \pm 57.35^{\mathrm{a}}$ & $670.41 \pm 86.91^{\mathrm{a}}$ \\
\hline
\end{tabular}

Different letters indicate statistically significant differences

$V L M$ virulent $L$. major, LMC L. major cold strain on host immune response against cutaneous leishmaniasis (caused by L. major), protection and healing of the lesions occurred when a high level of IFN- $\gamma$, IL-12, IL-2 and low levels of IL-4 and IL-5 were produced as a result of Th1 immune response activation $[5,18,33]$. The challenge of susceptible BALB/c mice with virulent amastigotes of $L$. major followed by $4 \times 10^{6} \mathrm{LMC}$ strain as a live-attenuated variety of $L$. major in the present study revealed a significant increase in IFN- $\gamma$ concentration. The findings of the present study demonstrated that induction of Th1 response by live-attenuated variety of $L$. major leads to milder histopathological alterations with a small number of Leishman bodies in skin lesions and liver sections in LMC group versus VLM group. Previous studies have presented a correlation between high levels of IgG2a with Th1 response and disease control $[4,40]$. High concentration of IgG2a in LMC group showed that immunization of mice with $4 \times 10^{6} \mathrm{LMC}$ strain induced high levels of immunogenicity and protection; therefore, protection was achieved in the experimental challenge group. Additionally, significant progress in wound healing was recorded in LMC group, whose lesion size at the injection site decreased when compared to lesions of VLM group. A similar study proved that dogs immunized with live-attenuated of $L$. donovani recovered from Leishmania infection in a very short period of time duration [13]. Data obtained from the present investigation are also in agreement with the previous studies [32,36, 38]. Also, our results are in consistency with the data obtained from immunization of BALB/c mice with live attenuated $L$. donovani [11]. In accordance with the results obtained from this study and the aforementioned studies, live-attenuated vaccines can be regarded as a potential strategic alternative against leishmaniasis. Live-attenuated vaccines with majority antigens and epitopes similar to a natural infection are capable of stimulating the host immune responses and induce the innate immune response of antigen-presenting cells [38]. In this study, LMC strain practically showed this leishmaniasis novel control approach could delete parasites and simultaneously enhance protective immunity against leishmaniasis. Consequently, we suggest that, in the future studies, more attention be directed at the attenuated vaccines for immunization against Leishmania parasites so that they be regarded as a potentially suitable vaccine candidate for the protection of the host against this disease. 
Fig. 6 a The IFN- $\gamma$ concentration produced by spleen cells in BALB/c mice. b The IL-4 concentration produced by spleen cells in $\mathrm{BALB} / \mathrm{c}$ mice. $V L M$ virulent $L$. major, $L M C L$. major cold strain

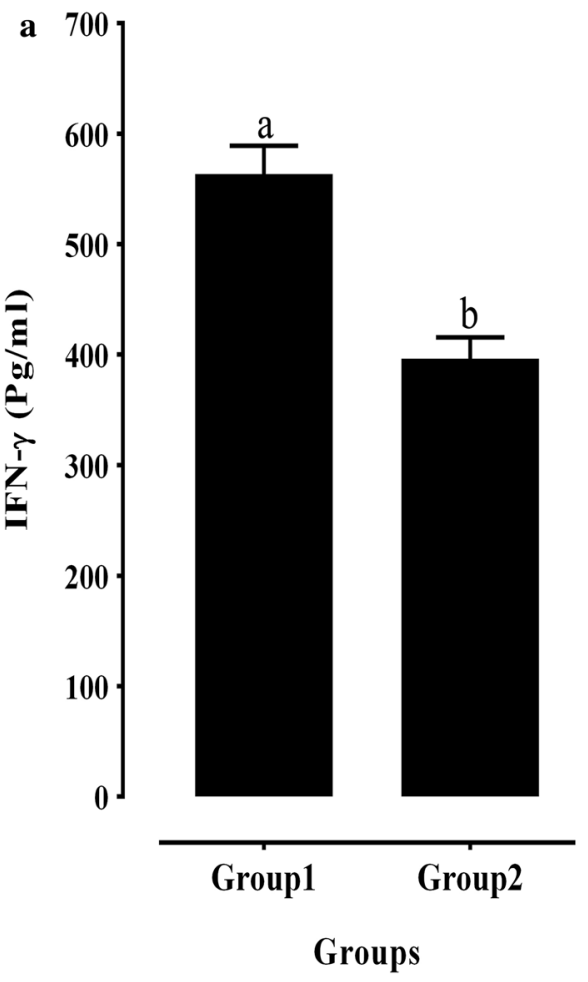

Acknowledgements This work was supported by the Research Council of Shiraz University and School of Veterinary Medicine, Shiraz University (94GCU5M83832) and the Razi Vaccine and Serum Research Institute, Shiraz Branch, Agricultural Research, Education and Extension Organization (AREEO).

\section{Compliance with Ethical Standards}

Conflict of Interest The authors have no competing interests.

\section{References}

1. Alvar J, Velez ID, Bern C, Herrero M, Desjeux P, Cano J et al (2012) Leishmaniasis worldwide and global estimates of its incidence. PLoS One 7:e35671

2. Asadi-Manesh R (2016) Histopathological and immunogenic study of Leishmania major LMC strain in inbred Balb/c mice. DVM Thesis. Shiraz University, Iran

3. Badiee A, Jaafari MR, Khamesipour A (2007) Leishmania major: immune response in BALB/c mice immunized with stress-inducible protein 1 encapsulated in liposomes. Exp Parasitol 115:27-134

4. Baptista-Fernandes T, Marques C, Rodrigues OR, Santos-Gomes GM (2007) Intra-specific variability of virulence in Leishmania infantum zymodeme MON-1 strains. Comp Immunol Microbiol Infect Dis 30:41-53

5. Boom WH, Liebster L, Abbas A, Titus R (1990) Patterns of cytokine secretion in murine leishmaniasis: correlation with disease progression or resolution. Infect Immun 58:3863-3870

6. Campos-Neto A, Webb J, Greeson K, Coler R, Skeiky Y, Reed S (2002) Vaccination with plasmid DNA encoding TSA/LmSTI1 leishmanial fusion proteins confers protection against Leishmania major infection in susceptible BALB/c mice. Infect Immun 70:2828-2836

7. Coler RN, Reed SG (2005) Second-generation vaccines against leishmaniasis. Trends Parasitol 21:244-249

8. Connell ND, Medina-Acosta E, McMaster WR, Bloom BR, Russell DG (1993) Effective immunization against cutaneous leishmaniasis with recombinant bacille Calmette-Guerin expressing the Leishmania surface proteinase gp63. Proc Natl Acad Sci USA 90:11473-11477

9. Cox FE (1996) The Wellcome Trust illustrated history of tropical diseases. Wellcome Trust, London

10. Croft SL, Coombs GH (2003) Leishmaniasis-current chemotherapy and recent advances in the search for novel drugs. Trends Parasitol 19:502-508

11. Dey R, Dagur PK, Selvapandiyan A, McCoy JP, Salotra P, Duncan R, Nakhasi HL (2013) Live attenuated Leishmania donovani p27 gene knockout parasites are nonpathogenic and elicit long-term protective immunity in BALB/c mice. J Immunol 190:2138-2149

12. Dunning N (2009) Leishmania vaccines: from leishmanization to the era of DNA technology. Biosci Horizons 2:73-82

13. Fiuza JA, Gannavaram S, da Costa Santiago H, Selvapandiyan A, Souza DM, Passos LS et al (2015) Vaccination using live attenuated Leishmania donovani centrin deleted parasites induces protection in dogs against Leishmania infantum. Vaccine 33:280-288

14. Gibson-Corley KN, Olivier AK, Meyerholz DK (2013) Principles for valid histopathologic scoring in research. Vet Pathol 50(6):1007-1015

15. Gillespie PM, Beaumier CM, Strych U, Hayward T, Hotez PJ, Bottazzi ME (2016) Status of vaccine research and development of vaccines for leishmaniasis. Vaccine 34:2992-2995

16. Handman E (2001) Leishmaniasis: current status of vaccine development. Clin Microbiol Rev 14:229-243

17. Hashemi-Fesharaki R, Ale-Agha S, Habibi G, Manhouri H, Esmail-Nia K, Mohammadi A (1998) Production of inactivated wet rural Leishmania major. Iran J Med Sci 23:74-80 
18. Jaafari MR, Ghafarian A, Farrokh-Gisour A, Samiei A, Kheiri MT, Mahboudi F et al (2006) Immune response and protection assay of recombinant major surface glycoprotein of Leishmania (rgp63) reconstituted with liposomes in BALB/c mice. Vaccine 24:5708-5717

19. Khalil EA, El Hassan AM, Zijlstra EE, Mukhtar MM, Ghalib HW, Musa B et al (2000) Autoclaved Leishmania major vaccine for prevention of visceral leishmaniasis: a randomised, double-blind, BCG-controlled trial in Sudan. Lancet 356:1565-1569

20. Khamesipour A, Dowlati Y, Asilian A, Hashemi-Fesharki R, Javadi A, Noazin S et al (2005) Leishmanization: use of an old method for evaluation of candidate vaccines against leishmaniasis. Vaccine 23:3642-3648

21. Lage DP, Martins VT, Duarte MC, Costa LE, Garde E, Dimer LM et al (2016) A new Leishmania-specific hypothetical protein and its non-described specific B cell conformational epitope applied in the serodiagnosis of canine visceral leishmaniasis. Parasitol Res 115:1649-1658

22. Liu D, Kebaier C, Pakpour N, Capul AA, Beverley SM, Scott P et al (2009) Leishmania major phosphoglycans influence the host early immune response by modulating dendritic cell functions. Infect Immun 77:3272-3283

23. Lowry OH, Rosebrough NJ, Farr AL, Randall RJ (1951) Protein measurement with the Folin phenol reagent. J Biol Chem 193:265-275

24. Mayrik W, Botelho ACdC, Magalhães PA, Batista SM, Lima AdO, Genaro $\mathrm{O}$ et al (2006) Immunotherapy, immunochemotherapy and chemotherapy for American cutaneous leishmaniasis treatment. Rev Soc Bras Med Trop 39:14-21

25. McMahon-Pratt D, Rodriguez D, Rodriguez J, Zhang Y, Manson $K$, Bergman $C$ et al (1993) Recombinant vaccinia viruses expressing GP46/M-2 protect against Leishmania infection. Infect Immun 61:3351-3359

26. Modabber F (1989) Experiences with vaccines against cutaneous leishmaniasis: of men and mice. Parasitology 98:S49-S60

27. Momeni AZ, Jalayer T, Emamjomeh M, Khamesipour A, Zicker F, Ghassemi RL et al (1999) A randomised, double-blind, controlled trial of a killed $L$. major vaccine plus BCG against zoonotic cutaneous leishmaniasis in Iran. Vaccine 17:466-472

28. Nadim A, Javadian E, Tahvildar-Bidruni G, Ghorbani M (1982) Effectiveness of leishmanization in the control of cutaneous leishmaniasis. Bull de la Société de Pathologie Exotique 76:377-383

29. Noazin S, Modabber F, Khamesipour A, Smith PG, Moulton LH, Nasseri K et al (2008) First generation leishmaniasis vaccines: a review of field efficacy trials. Vaccine 26:6759-6767

30. Okwor I, Uzonna J (2009) Vaccines and vaccination strategies against human cutaneous leishmaniasis. Human Vaccine 5:291-301

31. Ramírez L, Santos DM, Souza AP, Coelho EA, Barral A, Alonso $\mathrm{C}$ et al (2013) Evaluation of immune responses and analysis of the effect of vaccination of the Leishmania major recombinant ribosomal proteins L3 or L5 in two different murine models of cutaneous leishmaniasis. Vaccine 31:1312-1319

32. Rivier D, Shah R, Bovay P, Mauel J (1993) Vaccine development against cutaneous leishmaniasis. Subcutaneous administration of radioattenuated parasites protects CBA mice against virulent Leishmania major challenge. Parasite Immunol 15:75-84

33. Sacks D, Noben-Trauth N (2002) The immunology of susceptibility and resistance to Leishmania major in mice. Nat Rev Immunol 2:845-858

34. Sadick MD, Heinzel FP, Holaday BJ, Pu RT, Dawkins RS, Locksley RM (1990) Cure of murine leishmaniasis with anti-interleukin 4 monoclonal antibody. Evidence for a T cell-dependent, interferon gamma-independent mechanism. J Exp Med 171:115-127

35. Scott P, Pearce E, Natovitz P, Sher A (1987) Vaccination against cutaneous leishmaniasis in a murine model. I. Induction of protective immunity with a soluble extract of promastigotes. J Immunol 139:221-227

36. Selvapandiyan A, Dey R, Gannavaram S, Solanki S, Salotra P, Nakhasi HL (2014) Generation of growth arrested Leishmania amastigotes: a tool to develop live attenuated vaccine candidates against visceral leishmaniasis. Vaccine 32:3895-3901

37. Selvapandiyan A, Dey R, Nylen S, Duncan R, Sacks D, Nakhasi HL (2009) Intracellular replication-deficient Leishmania donovani induces long lasting protective immunity against visceral leishmaniasis. J Immunol 183:1813-1820

38. Silvestre R, Cordeiro-da-Silva A, Ouaissi A (2008) Live attenuated Leishmania vaccines: a potential strategic alternative. Arch Immunol Ther Exp 56:123

39. Srivastava S, Shankar P, Mishra J, Singh S (2016) Possibilities and challenges for developing a successful vaccine for leishmaniasis. Parasites Vectors 9:277

40. Tewary P, Sukumaran B, Saxena S, Madhubala R (2004) Immunostimulatory oligodeoxynucleotides are potent enhancers of protective immunity in mice immunized with recombinant ORFF leishmanial antigen. Vaccine 22:3053-3060

41. Tonui WK, Mejia JS, Hochberg L, Mbow ML, Ryan JR, Chan AS et al (2004) Immunization with Leishmania major exogenous antigens protects susceptible $\mathrm{BALB} / \mathrm{c}$ mice against challenge infection with $L$. major. Infect Immun 72:5654-5661

42. Uzonna JE, Joyce KL, Scott P (2004) Low dose Leishmania major promotes a transient $\mathrm{T}$ helper cell type 2 response that is downregulated by interferon $\gamma$-producing CD8 $+\mathrm{T}$ cells. J Exp Med 199:1559-1566

43. Zahedifard F, Gholami E, Taheri T, Taslimi Y, Doustdari F, Seyed $\mathrm{N}$ et al (2014) Enhanced protective efficacy of nonpathogenic recombinant Leishmania tarentolae expressing cysteine proteinases combined with a sand fly salivary antigen. PLoS Negl Trop Dis 8:e2751

44. Zandieh M, Kashi T, Taheri T, Zahedifard F, Taslimi Y, Doustdary $M$ et al (2015) Assessment of protection induced by DNA and live vaccine encoding Leishmania MHC class I restricted epitopes against $L$. major challenge in Balb/c mice model. J Microb Biochem Technol 7(6):427-438

Publisher's Note Springer Nature remains neutral with regard to jurisdictional claims in published maps and institutional affiliations. 